International Journal of Engineering, Science and Technology

Vol. 5, No. 1, 2013, pp. 28-41
INTERNATIONAL JOURNAL OF ENGINEERING, SCIENCE AND TECHNOLOGY

www.ijest-ng.com

www.ajol.info/index.php/ijest

(C) 2013 Multicraft Limited. All Rights Reserved

\title{
Comparison of wind pressure measurements on Silsoe experimental building from full-scale observation, wind-tunnel experiments and various CFD techniques
}

\author{
H. Irtaza ${ }^{1}$, R.G. Beale ${ }^{2}$, M.H.R. Godley ${ }^{2}$, A. Jameel ${ }^{3}$ \\ ${ }^{1}$ Department of Civil Engineering, Aligarh Muslim University, Aligarh 202002, INDIA \\ ${ }^{2}$ Faculty of Technology, Design and Environment, Oxford Brookes University, Oxford, U.K. \\ ${ }^{3}$ University Polytechnic, A.M.U., Aligarh 202002, INDIA \\ Corresponding Author: E-mail: hirtaza.amu@gmail.com, h_irtaza@yahoo.co.in; Tel. Nos. (H Irtaza), +91-571-2703356, (m): +91-8126710884
}

\begin{abstract}
The paper is the result of extensive research concentrated on analyzing the accuracy and numerical stability to assess the various turbulence models available widely and the state of the art techniques for the numerical simulation of turbulent fluid flow with a view of finding the most appropriate models for computational wind engineering. These investigations suggest that a turbulence model, suitable for wind engineering applications, should be able to model the anisotropy of turbulent flow while maintaining the ease of use and computational stability. Keeping this in mind five turbulence models such as Standard $k-\varepsilon$, RNG $k-\varepsilon$, Realizable $k-\varepsilon$, Reynolds Stress Method and Large Eddy Simulation have been tested in an attempt to account for anisotropic turbulence and curvature related strain effects and the same have been compared with the full-scale and wind-tunnel data for the present study. Better turbulence models that will be more accurately predict bluff body flow fields and that are numerically stable for complex geometries are of paramount importance if the uses of CFD techniques are to gain wide acceptance by the wind engineering community.
\end{abstract}

Keywords: Silsoe Experimental Building, CFD, Low-rise building, Wind-tunnel

DOI: http://dx.doi.org/10.4314/ijest.v5i1.3

\section{Introduction}

Computational Fluid Dynamics (CFD) has been developed rapidly over the last three decades with the advent of high speed digital computer technology to evaluate the interaction between wind and structures numerically, which are described mathematically by a set of coupled non-linear partial differential equations and the appropriate boundary conditions, in a relatively short space of time and for a low financial cost offering an alternative technique for practical applications in wind engineering. Initially the wind engineering community largely ignored this technique due to the errors in early modelling techniques and the need for powerful computers (Wright and Easom, 2003), but in the early 1990s enabled CFD to be applied to the complex field of wind engineering due to the advent of high speed digital computer at affordable/reduced cost. This area of study will take few more decades to develop fully particularly in its application to Computational Wind Engineering (CWE) where wind flows externally are normally considered.

Computational fluid dynamic techniques such as the Reynolds Averaged Navier-Stokes Equations (RANS) models, the Large Eddy Simulation (LES) etc., have been used to predict the wind flows around the bluff body. There were many difficulties such as large Reynolds number, impinging at the front, remaining effect of flow obstacles at outflow boundary etc., while analyzing the flow around the sharp edged bluff body using computational fluid dynamics techniques as reviewed by Murakami (1998). Many efforts have been devoted by various researchers to overcome the problem in turbulence modeling, the wall boundary conditions and the over production of turbulent kinetic energy near the sharp edges. The various RANS techniques of turbulence modeling are the Standard $k-\varepsilon$, the RNG $k-\varepsilon$ and the Realizable $k-\varepsilon$ have nearly similar forms with transport equations for $k$ and $\varepsilon$, howev- 
er, there are major differences in calculating turbulent viscosity and the production and dissipation of turbulent kinetic energy while modeling turbulence. The standard $k-\varepsilon$ model proposed by Launder and Spalding (1972) is a semi-empirical model based on model transport equations for the turbulence kinetic energy $(k)$ and its dissipation rate $(\varepsilon)$. It has been recognized widely that the Standard $k-\varepsilon$ can predict the general wind conditions around building reasonably well except those in the separation regions above roof surface and side walls and can be attributed to the overestimation of turbulence energy. As the strengths and weaknesses of the Standard $k-\varepsilon$ model became known, improvements were made to the turbulence model to improve its performance and in this sequence the RNG $k-\varepsilon$ turbulence model by Yakhot and Orszag (1986) and the Realizable $k-\varepsilon$ turbulence model by Shih et al. (1995) were developed.

The RNG-based $k-\varepsilon$ turbulence model is derived using a rigorous statistical technique, called renormalization group theory, from the instantaneous Navier-Stokes equations. The RNG model has an additional term in its $\varepsilon$ equation that significantly improves the accuracy for rapidly strained flows. Effect of swirl on turbulence, analytical formula for turbulent Prandtl numbers and an analytically-derived differential formula for effective viscosity to accounts for low Reynolds number effect (analytical derivation results in a model with constants different from those in the standard $k-\varepsilon$ model) is also included in RNG-based $k-\varepsilon$ turbulence model (Fluent, 2006). These features make the RNG $k-\varepsilon$ model more accurate and reliable, gives better results for a wider class of flows than the Standard $k-\varepsilon$ model. The Realizable $k-\varepsilon$ turbulence model has been developed recently and has not been tested much for external flows at high Reynolds number. Also it is not clear in exactly which instances the Realizable $k-\varepsilon$ model consistently outperforms the RNG model. It has new formulation both for the turbulent viscosity and transport equation for the dissipation rate and has been derived from the exact equation for transport of the mean-square vorticity fluctuation (Fluent, 2006). Initial studies have shown that the Realizable $k-\varepsilon$ model better predicts the pressure forces for flows involving rotation, boundary layers under strong and adverse pressure gradients, separation and recirculation.

The Reynolds stress model (RSM) is the most elaborate turbulence model closes the Reynolds-averaged Navier-Stokes equations by solving transport equations for the Reynolds stresses, together with an equation for the dissipation rate. Five and seven additional transport equations are required in 2D and 3D flows respectively, thus requiring additional memory and CPU time due to the increased number of the transport equations for Reynolds stresses. RSM is useful for the study of cyclone and highly swirling flows where the flow features of interest are the result of anisotropy in the Reynolds stresses (Fluent, 2006).RANS models have been used in wind engineering applications due to their simplicity and efficiency. However, with the advancement in computational resources, the Large Eddy Simulation (LES) have attracted attention in wind engineering as it is capable of simulating complex unsteady turbulent flows around a surface-mounted cube fairly well, which is useful for investigating wind-induced vibrations of building and structures at the price of paying a larger computational effort. This is an intermediate form of turbulence calculations in which large eddies are explicitly computed (by modeling less of the turbulence and resolving more) in a time dependent simulation using the 'filtered' Navier-Stokes equations and the error introduced by turbulence modelling can be reduced.

Murakami (1998) in his paper 'overview of turbulence models applied in CWE' stated that the LES with a dynamic sub-gridscale (SGS) model is a promising tool for accurately predicting the flow field around a bluff body compared with other turbulence models. For solving practical problems there are certain limitations in choosing SGS models to be applied effectively for the LES, However, none of the SGS models are fully satisfactory (Huang et al., 2007). The other limitation in LES is the near wall treatment. Very fine grid resolutions are required especially for separated boundary layer flows, which makes full-scale LES often in applicable due to the huge amount of mesh numbers required. The LES technique thus falls between the Direct Numerical Simulation (DNS) and the RANS model in terms of the fraction of the resolved scales.

Rodi (1993) reviews calculations performed to-date of vortex-shedding flow past long cylinders at high Reynolds numbers. The Algebraic Eddy-viscosity models to the Reynolds-stress-equation models were summarized and discussed, and calculations of vortex-shedding flow past cylinders of various cross-sections were presented and then confronted with large-eddy simulations whenever possible, and a comparative discussion on the various calculation methods was given. Richards and Hoxey suggested new model constants for $k-\varepsilon$ turbulence model and appropriate boundary conditions for computational wind engineering models (Richards and Hoxey, 1993).

Frank and Mauch (1993) developed a numerical program to calculate incompressible, unsteady, three-dimensional viscous and turbulent flow fields around sharp edged obstacles. The purpose of our work was to apply the concept of LES to practical problems in building aerodynamics. The numerical results were compared with different experimental data with good agreement (Frank and Mauch, 1993). Analyses by CFD on unsteady flow fields past a two-dimensional (2D) square cylinder was reviewed by Murakami and Mochida (1995). Firstly, the comparison of the results of large eddy simulation (LES) for 2D and 3D computations were described. The LES results given from 3D computation agreed very well with the experimental results, but the results based on 2D computation were different from those based on 3D computation as well as from those given from experiments. Rodi (1997) compared the LES and RANS calculations of vortex-shedding flows past a square cylinder and a surface mounted cube at $R_{e}=22,000$ and $R_{e}=40,000$ respectively and concluded that the $k-\varepsilon$ model strongly under-predicted the periodic motion due to excessive turbulence productions. Ghosh (2004) reviewed the computational method used in solving wind engineering problems mainly related to wind flow over bluff bodies. Air approach flow moving towards a cube was studied using computational fluid dynamics by Gao and Chow (2005).

Hoffman and Johnson (2006) presented a new approach to computational fluid dynamics using adaptive stabilized Galerkin finite element methods with duality based a posteriori error control for chosen output quantities of interest. Huang et al. (2007) pre- 
sented extensive study on the wind effects on the Commonwealth Advisory Aeronautical Council (CAARC) building using various techniques of Computational Fluid Dynamics and the same were compared with extensive experimental data obtained from seven wind-tunnel tests on CAARC building.

It is therefore apparent that one of the main obstacles to the use of CFD in wind engineering is that of turbulence modeling. In view of this shortcoming the aim of this work has been to conduct research into the various turbulence modelling methods available with a view to developing improved turbulence models for computational wind engineering.

\section{Full-Scale Data from Silsoe}

The full scale Silsoe Experimental Building (SEB) shown in Figure 1 is situated at the Silsoe Research Institute (SRI) in an exposed position in relatively flat terrain in South Bedfordshire. It was constructed in the late 1990s to allow the comparison of full scale rather than model scale wind tunnel data. It was positioned so that the boundary layer was generated from a fetch consisting of short grass with an effective roughness length of $0.006 \mathrm{~m}-0.01 \mathrm{~m}$. This means that the cube had a Jensen number of $600-$ 1000.The effective roughness length of the fetch is nearly constant due to regular cutting of the grass (Kasperski and Hoxey, 2008). The velocity profile at the Silsoe Research Institute site (as shown in Figure 2) was measured at various times (Richards et al., 2007) and is well matched by a simple logarithmic profile. The longitudinal turbulence intensity at the roof height was typically around 18\% (Richards et al., 2007) as shown in Figure 3.
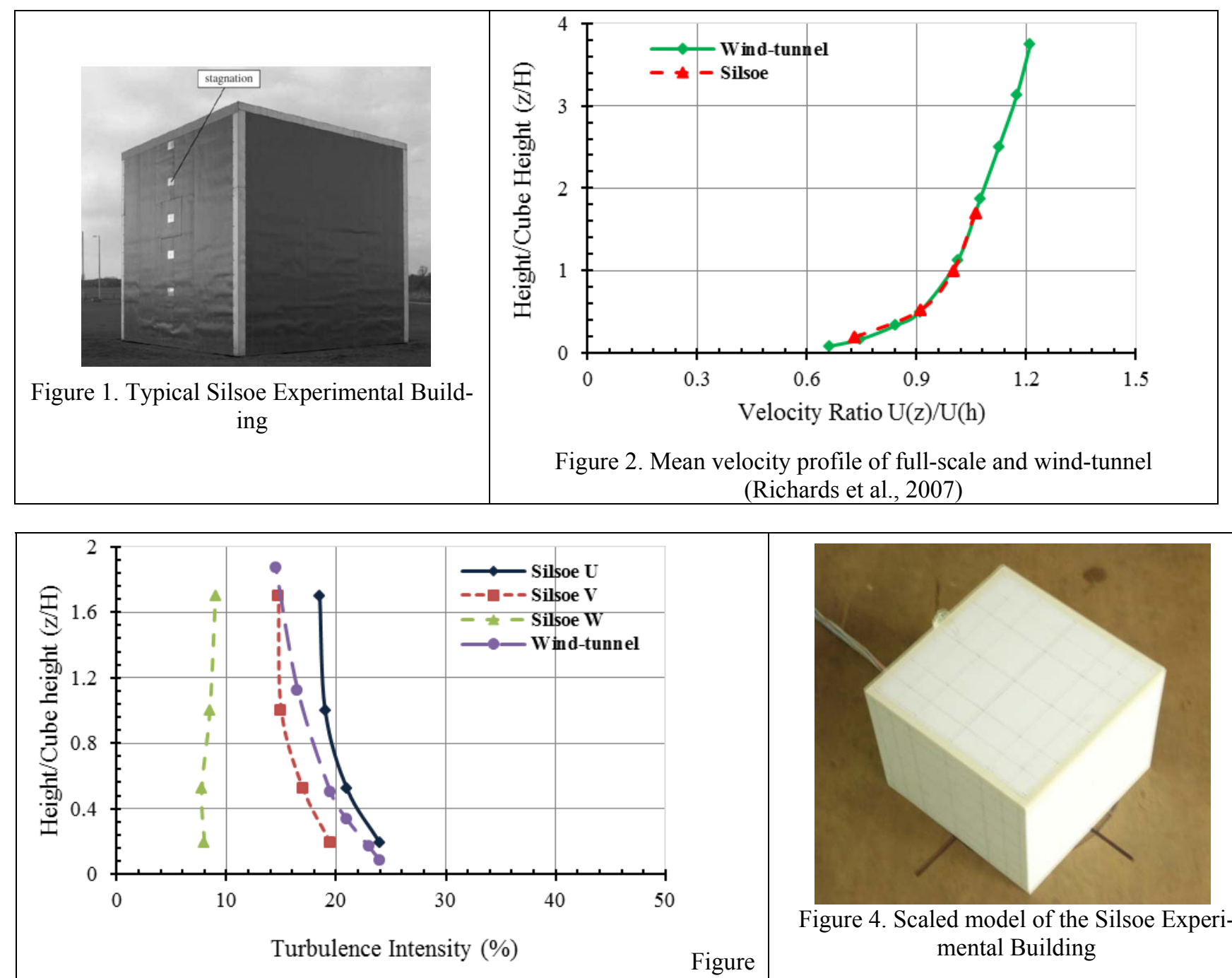

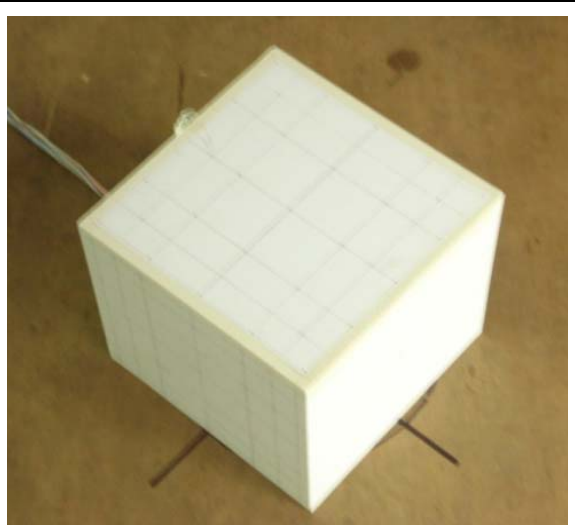

Figure 4. Scaled model of the Silsoe Experimental Building

3. Turbulent intensity profile comparison between full-scale and windtunnel (Richards et al., 2007)

The cubical SEB could be rotated through $360^{\circ}$ and pitched on the horizontal axis by $5^{\circ}$. It was instrumented with 32 surface tapping points on a vertical and horizontal centerline section on the windward face, roof and leeward face with additional tappings on one quarter of the roof as shown in Figure 1. The wind dynamic pressure and direction could be derived simultaneously from an ultrasonic anemometer positioned $25 \mathrm{~m}$ upstream of the building at roof height. The tapping points were constructed of simple 
$7 \mathrm{~mm}$ diameter holes (a size sufficient to prevent water blocking the tapping points) and the pressure signals were transmitted pneumatically, using a $6 \mathrm{~mm}$ internal diameter plastic tube to transducers mounted centrally within the cube. Tube lengths of up to 10 meters were used in this system giving a frequency response of $3 \mathrm{~dB}$ down at $8 \mathrm{~Hz}$ (Richards and Hoxey, 2008). A 36 minutes record length he used (9000 samples) which he sub-divided into three 12 minute segments. These were processed to give all the required experimental data including mean, fluctuating and spectral properties and can be found in the work by Richards and Hoxey (2008).

\section{Wind-tunnel Study on the Model of the Cubical SEB}

The SEB of dimension $6 \mathrm{~m} \times 6 \mathrm{~m} \times 6 \mathrm{~m}$ was used as a base model for the wind-tunnel experiments. A scale of 1:30 was used to make the model of dimension $0.2 m \times 0.2 m \times 0.2 m$ to determine the wind forces by conducting wind-tunnel experiments as shown in Figure 4. It was fabricated using $2 \mathrm{~mm}$ thick white acrylic plastic. Stainless steel tubing pressure taps were used which were 10 $\mathrm{mm}$ long, $1.0 \mathrm{~mm}$ external diameter and $0.9 \mathrm{~mm}$ internal diameter. They were inserted into holes drilled in the plastic sheeting with one end of the tap flush with the wall/roof surface. The tubing for measuring the pressures consisted of $300-400 \mathrm{~mm}$ vinyl tubes.

The wind-tunnel used for testing the models was a $26 \mathrm{~m}$ long open type atmospheric boundary layer under the auspices of Department of Civil Engineering, Hong Kong Polytechnic University, Hong Kong (RED Consultants, Hong Kong). The test section was $17.5 \mathrm{~m}$ long, $3.3 \mathrm{~m}$ wide and $2.2 \mathrm{~m}$ high. The roof of the test section could be raised up to a maximum height of $0.6 \mathrm{~m}$ to keep the pressure constant in longitudinal direction if required. The diameter of the turn table was $2.80 \mathrm{~m}$. The maximum wind speed in the test section was around $15 \mathrm{~m} / \mathrm{s}$. The atmospheric boundary layer was simulated by using artificial roughness arranged in staggered array on the test floor of the wind-tunnel platform with spires and baffles. The wind pressures were measured by a high frequency electronic pressure scanner which could measure simultaneously wind pressure at up to 64 locations.

To obtain the wind pressure distribution on the walls of the SEB model, sufficient number of pressure transducers were installed to include all surface details and to comply with the requirement. It was the rainy season in Hong Kong during the experimental work. Most of the time it was either raining or the humidity of the air was more than $90 \%$ during recording of most of the observations in the wind-tunnel. Natural wind was developed for the 1:30 scale model to simulate the wind over open country terrain. The simulation was done on the basis of Silsoe Research Institute (SRI) full-scale data from the work of Richards et al, 2007 (Richards et al., 2007). The velocity profile and the longitudinal turbulence intensities simulated in the wind-tunnel and data obtained from SRI site are shown in Figures 2 and 3. At a model scale of 1:30 it is well known that larger scales of turbulence due to wall constraints are missing and the turbulent energy is too large. The blockage ratio of the models within the tunnel was only $0.55 \%$. The outputs of the pressure sensors were electronically multiplexed through a single onboard instrumentation amplifier at rates up to $20,000 \mathrm{~Hz}$ using binary addressing. The multiplexed amplified analog output was capable of being driven through long lengths of cable to a remote $\mathrm{A} / \mathrm{D}$ converter. The sampling rate was kept at 100 samples per second per channel.

The average wind speed at the Silsoe site was $10 \mathrm{~m} / \mathrm{s}$ and of the model at eave height were $4.81 \mathrm{~m} / \mathrm{s}$. The velocity scale was therefore $10 / 4.81=2.08$. This meant the model time scale was $30 / 2.08=14.44$. Therefore one hour data in the field was equivalent to $3600 / 14.44=249$ seconds which was used as the duration of each run in the wind-tunnel. Note that the average wind speed in the wind-tunnel was recorded at model eave height and was calculated by taking the average of 18720 data points recorded over a period of 60 seconds in the wind-tunnel. The sampling rate of observation for wind speed in the wind-tunnel was 312 per second.

The average wind speeds over different heights were calculated and these speeds were used to find the profile of the wind used in the wind-tunnel. The mean longitudinal wind speed profile measured in the wind-tunnel was in good agreement with the SRI full-scale profile with a power-law exponent of 0.17. The longitudinal turbulence was slightly less than the SRI full-scale data. Many iterations (by changing the size and position of roughness) were undertaken to achieve the same turbulence at the model height during the testing process but was not possible to achieve the exact turbulence.

The small-scale turbulence content (S) (Saathoff and Mebourne, 1986) defined as $S=\left[n S_{u}(n) / \sigma_{u}^{2}\right] \cdot\left[\sigma_{u} / U\right]^{2} \times 10^{6}$ evaluated at $n=10 U / L_{p}$ where $n$ is frequency, $S_{u}(n)$ is spectral density, $\sigma_{u}$ is the standard deviation of the longitudinal mean velocity $(U)$ and $L_{p}$ is the characteristic model dimension, was found to be 89 . This value compares favourably with a value of 85 found by Ahmad and Kumar (2002) when producing wind-tunnel models of hipped roofs. The model eave height was taken as the characteristic dimension. The reduced spectra plot at the model eave height is shown in Figure 5. The reduced spectrum plot shown in the figure has not matched the profiles commonly observed in wind-tunnels. This may be due to fluctuations on cross-aisle directions which were not measured in the tunnel. However, as shown in Figure 3, the observed wind-tunnel turbulence was in general agreement with that of the Silsoe site. The integral scale in the wind tunnel was also evaluated at the model eave height for the longitudinal wind speed and found to be $0.30 \mathrm{~m}$. The integral scale is defined as the area under the auto-correlation curve of the fluctuating velocity component. Since the auto-correlation measurements are usually temporal measurements at a fixed point, the integral length scale, $L_{u x}$, was evaluated by using:

$$
L_{u x}=U \int_{0}^{\infty} R(\tau) d \tau
$$


where, $U$ is the mean wind speed, $\tau$ is the time and $\int_{0}^{\infty} R(\tau) d \tau$ is the area under the auto-correlation curve as shown in Figure 6 (Scruton, 1981).

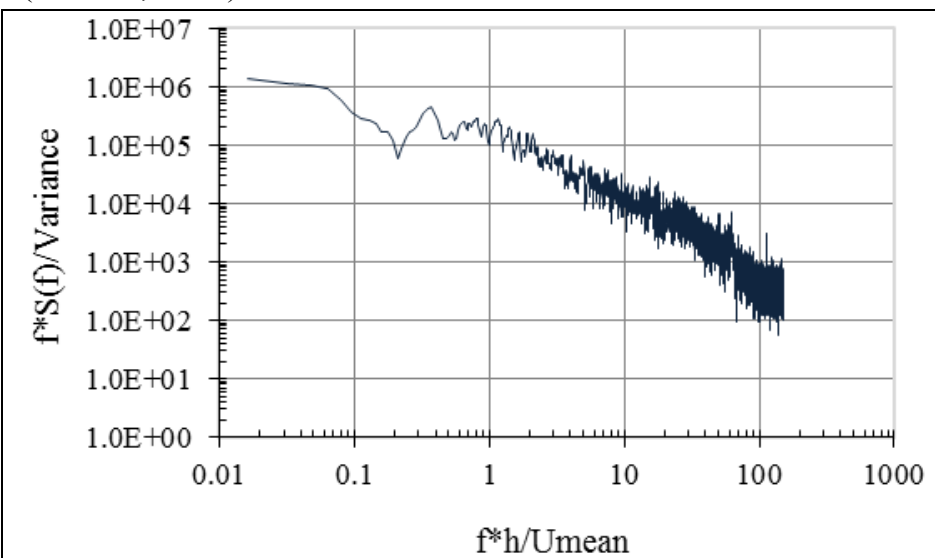

Figure 5. Normalized reduced spectrum plot at eave height

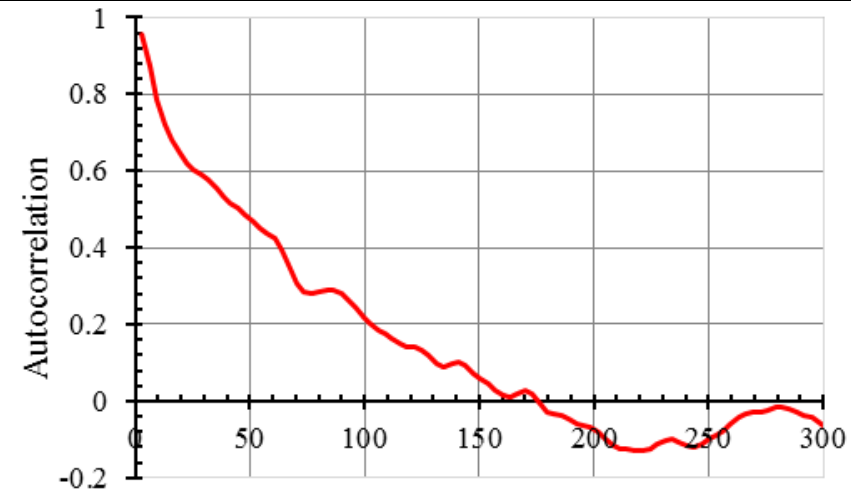

Time in millisecond

Figure 6. Auto-correlation plot at eave height

However, the auto-correlation function is often highly oscillatory and hence the area under the curve tends to cancel out, which produces an unrealistically small length scale. This problem was overcome in the usual manner by defining the integral scale as the area under the auto-correlation curve for the value occurring before the first zero crossing as recommended by Panofsky and Dutton (1984).

For each run, wind pressures measured on the models were expressed in the form of a non-dimensional pressure coefficient, defined as:

$$
C_{p}(t)=\frac{p(t)-p_{0}}{\frac{1}{2} \rho U^{2}}
$$

where, $p_{0}$ is the static (ambient/atmospheric) reference pressure, $U$ the mean longitudinal wind speed at the reference height (eave height) and $\rho$ the air density.

The location of pressure taps on the roof and on the vertical wall face are shown in the Figures 7 and 8 . A total of 61 taps (31 taps on the roof +30 taps on a vertical wall face) were used to record the observations on the scale model of SEB. Additional pressure taps were installed on two other faces to counter check the recordings of pressures. The instantaneous wind pressures on each location of the model were tested at every 15 degrees angle of rotation of the turn-table to produce a set of 24 observations around the building. The mean, RMS (root-mean-squares) and the maximum and minimum pressure coefficients were derived from the wind tunnel data. The maximum and minimum pressures were determined by using the method proposed by Cook and Mayne, (1981). The maximum and minimum pressures are representative of the wind pressure of 4 minutes 9 seconds (equal to hourly wind data in the field) averages.

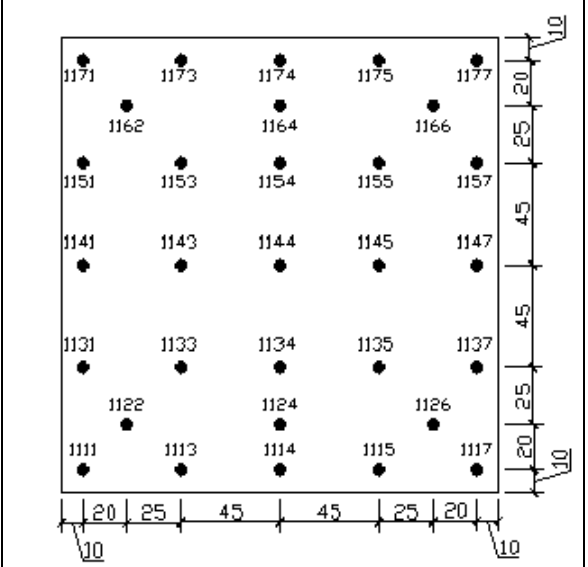

Figure 7. Pressure taps positions on the roof of SEB model

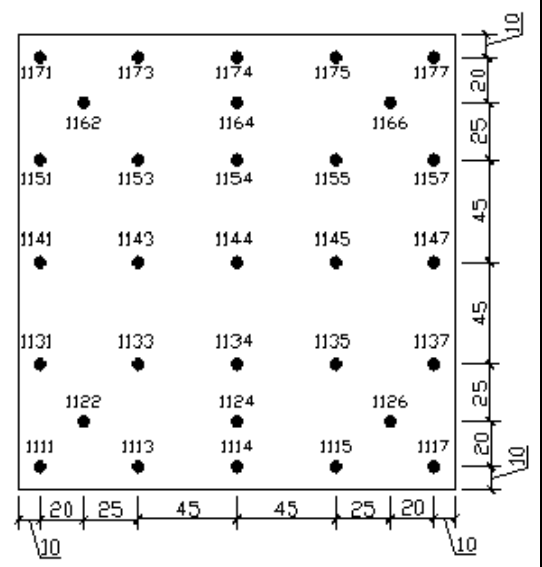

Figure 8. Pressure taps positions on the south wall face of the model 


\section{Computational Solution Strategies}

A scale of 1:30 of SEB was also used for the computational simulation. The computational domain covers $29 B$ (where $B$ is the length or width of the model) in the stream wise $X$ direction $[-6.5<(x / B)<22.5], 13 B$ in the lateral or normal $Z$ direction $[-6.5<(x / B)<6.5]$ and $4 H$ in the vertical $Y$ direction as shown in Figure 9. The percentage obstruction was 1.92 , which is less than $3 \%$ of maximum obstructions required for good wind-tunnel models and for CFD simulation. The reason for such a choice is to eliminate the flow obstacle effect on the inflow and outflow boundary conditions. The Reynolds numbers involved in the simulations were in the range of $0.72 \times 10^{5}$ to $1.09 \times 10^{5}$ for both wind-tunnel experiments and computational analyses.

Even if the building model is a simple cube, the generation of good quality mesh considering boundary layer conditions is very difficult and requires experience and number of iterations to achieve it. However, the number of mesh elements must be as low as possible for fast and efficient computation. The mesh near and aligned with the wall surfaces must be refined and stretched with the viscous boundary layer grid. The Fluent 6.30 code which was adopted in this study is based on the finite volume method (FVM), with the capacity of dealing both structured and unstructured grids in its solver (Irtaza et al, 2010). There are varieties of different methods of mesh generation in preprocessing software Gambit 2.6. Figures 10 to 11 show the mesh arrangement for the SEB model where both structured and unstructured meshes were used for the simulation. Unstructured meshes were generated in the core region around the scaled cubical SEB and structured meshes were generated for the rest of the domain. This arrangement makes it easier to generate a mesh fine enough in the neighbourhood of the model while keeping the mesh in zones far away from the model surfaces unchanged or in a proper coarse state. An important advantage of this arrangement is that the mesh aligned to the model surfaces does need to be stretched with the wall boundary layer grid as the structured mesh does.

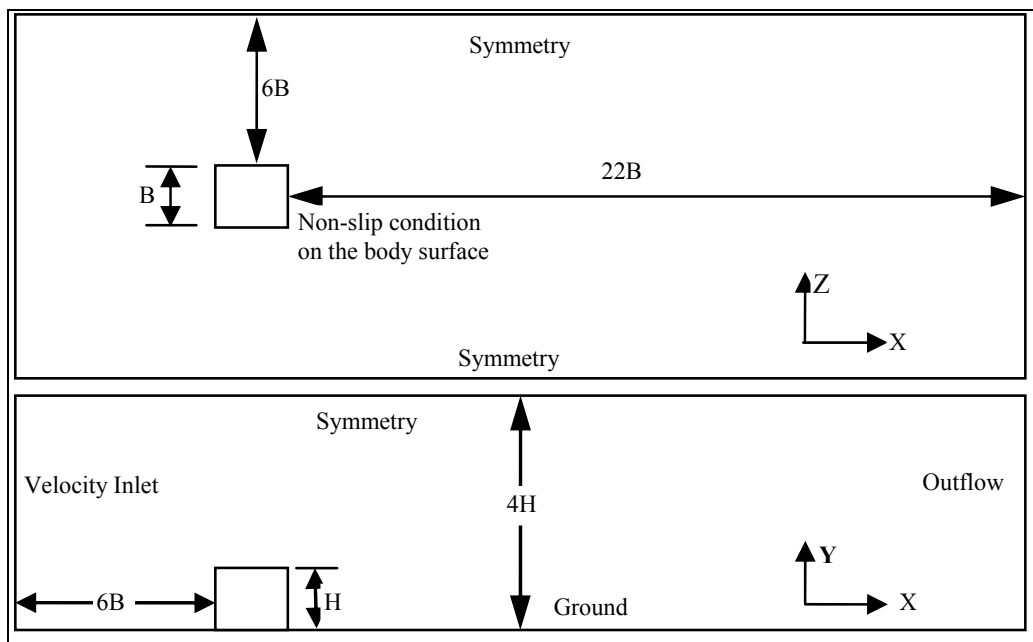

Figure 9. Computational domain and boundary conditions for the scaled cubical SEB
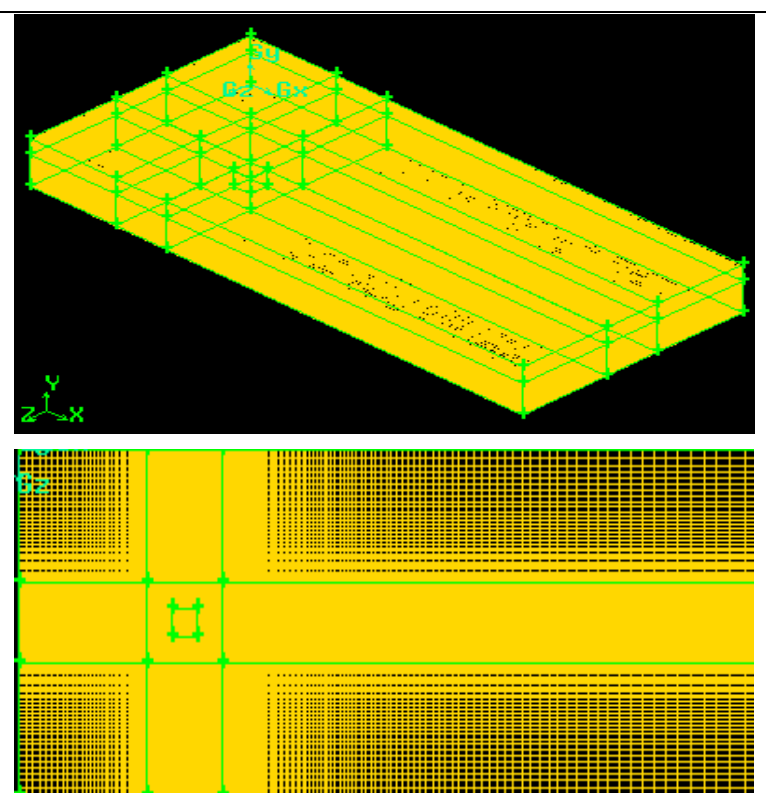

Figure 10. Overall grid distribution and grid distribution in plan

Wall boundary conditions were specified using wall functions on the surface of the building model. Viscous boundary layers were generated on the surface of the SEB with 20 grid layers. The height of the first cell of the boundary layer were chosen to be $0.084 \mathrm{~mm}$ to ensure wall unit $y^{+} \cong 1\left(y^{+}=\rho\right.$ uy $\left./ \mu\right)$ for LES and a wall unit $y^{+}<5$ were used for all the RANS turbulence models.

The enhanced wall treatment were used as the value of $y^{+}$were less than 5 . Furthermore, grid dependent results were obtained by the mesh with 1.75 million to 4 million grid numbers for the computations by the RANS models and the LES. This is necessary to avoid the need for very fine grids to resolve the large energy dissipation gradients in the near wall region and thus reduce the computational overheads of a given wall bounded problem.

All the discretized equations are solved in a segregated manner with the Pressure Implicit with Splitting of Operators (PISO) algorithm. PISO is useful for unsteady flow problems and has a better performance for meshes containing cells with higher than average skewness. The second order implicit scheme is used for time discretization. Second order upwind discretization uses large stencils for $2^{\text {nd }}$ order accuracy, essential with triangular or tetrahedral meshes or when the flow is not aligned with the grid. The only drawback it has that if using second order upwind discretization then the convergence is slower (Fluent, 2006). 
It is very difficult to simulate the open wind characteristics exactly in a wind-tunnel. Even little differences in experimental conditions causes discrepancies between measurement results from different wind-tunnels. In order to obtain better agreement between experimental and numerical results, the boundary conditions adopted in the numerical simulations should be the same as those in the experiments, especially for the inflow boundary conditions (Huang et al., 2007).

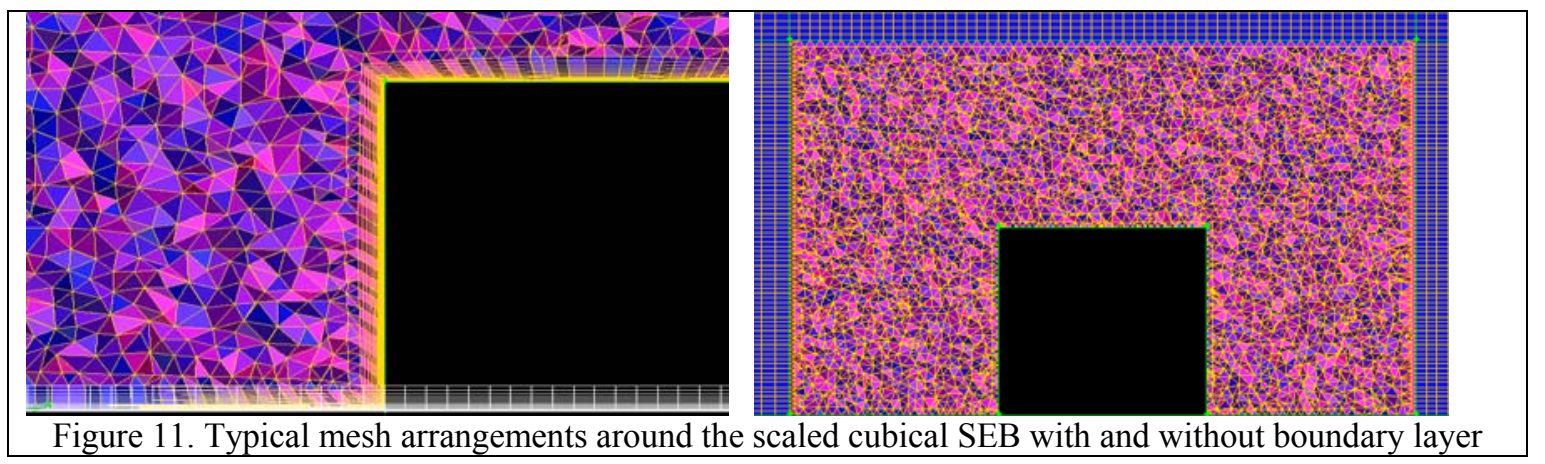

There are two kinds of expression to describe the velocity profile of atmospheric boundary layer simulated in wind tunnel tests. One is a power law and other is a log law. The velocity profile of the atmospheric boundary layer in the wind tunnel test conducted takes the following power law:

$$
U / U_{H}=\left(Z / Z_{H}\right)^{\alpha}
$$

where $U_{H}=4.81 \mathrm{~m} / \mathrm{s}$ was the wind speed at the eave height $(=0.2 \mathrm{~m})$ of the SEB model in the wind-tunnel experiments. $\alpha$ is the exponent of the velocity profile, which was 0.17 for the present case. The parameters derived from the present velocity profile for the present numerical simulation are $U_{\tau}=0.3246 \mathrm{~m} / \mathrm{s}, Z_{0}=10 \mathrm{~mm}$.

The log-law velocity profile was simulated for the inlet boundary conditions for the CFD analysis from the simulated atmospheric boundary layer in the wind-tunnel study is given as follows:

$$
\frac{U}{U_{\tau}}=\frac{1}{\kappa} \ln \left(\frac{Z+Z_{0}}{Z_{0}}\right)
$$

where $U_{\tau}$ is the friction velocity, $\kappa$ is Von Karman's constant and $Z_{0}$ is the surface roughness length parameter. Figure 12 shows the differences between wind-tunnel wind profile and the simulated wind profile for inlet boundary conditions for CFD analysis. The simulated wind profile for the CFD analysis nearly matches that of the wind profile simulated for the wind-tunnel testing.

The turbulence intensity profile should be properly modelled in order to obtain accurate simulation results because it has significant effect on the stream-wise distributions of the wind-induced pressures on the building model. The turbulence intensity profile of the wind-tunnel test conducted is shown in Figure 3.

The kinetic energy of turbulence and its dissipation rate at the inlet section were calculated according to the following equations:

$$
\begin{gathered}
k=\frac{3}{2}\left(U_{\text {avg }} I\right)^{2} \\
\varepsilon=C_{\mu}^{3 / 4} \frac{k^{3 / 2}}{l}
\end{gathered}
$$

where $U_{a v g}$ is the mean wind speed at inlet, $I$ is the turbulence intensity, which was interpolated from the profiles given in Figure 3 at different heights (a turbulence intensity of $18 \%$ at the eave height were kept constant for all the trials) and $l$ is the turbulence integral length scale. The value of $l$ measured in the wind-tunnel test at the model height was $0.30 \mathrm{~m}$.

Not only the information on mean velocity specification is needed in LES, but also information on the fluctuating velocity of incident wind is required. The spectral synthesizer in the Fluent code was used to generate fluctuating velocity components and is based on the random flow generation technique originally proposed by Kraichan and modified by Smirnov et al. (2001). In this method, fluctuating velocity components are computed by synthesizing a divergence-free velocity vector field from the summation of Fourier harmonics on the basis of the input turbulence boundary conditions. In the implementation of the Fluent code, the number of the Fourier harmonics is fixed to 100 (Fluent, 2006).

The entire computations were performed on the cluster of computer in the School of Technology, Oxford Brookes University in Oxford, UK. A total of 25 CPUs (Core 2 Duo) were used in parallel for the simulations. The numerical time step for all the RANS techniques were $0.001 \mathrm{~s}, 4000$ time steps were iterated (20 iterations per time step), whereas, for LES technique the time step was $0.0005 \mathrm{~s}, 5000$ to 8000 time steps were iterated (20 iterations per time step) to obtain time-averaged results. All the above models were run for unsteady computations over a period of 4 seconds. 


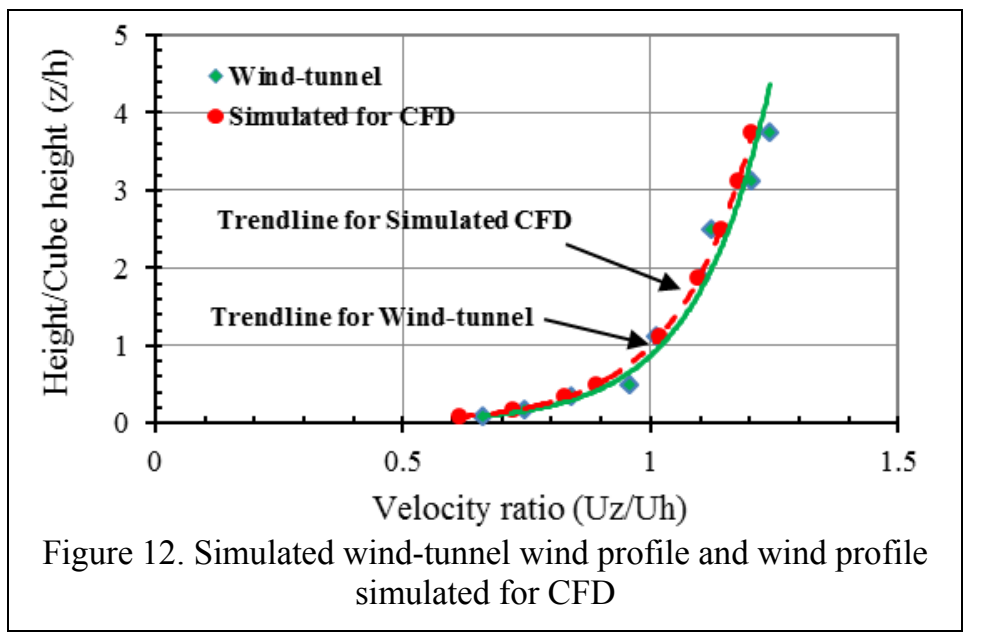

\section{Discussion}

The SEB was taken as the base model for study as the full-scale data, i.e. the velocity profile and longitudinal turbulence intensities from the Silsoe site, were available to be used both for the experiment (for simulation in a wind-tunnel) and for CFD analyses.

The models were tested in the wind tunnel at every 15 degrees of angle to determine the mean, maximum +ve, maximum -ve and rms pressure coefficients on its façade (Irtaza et al, 2010). The pressure contours on the roof of the building are shown in Figures 13 to 17 for $0^{\circ}$ to $45^{\circ}$ angle of incidence and that on the façade of the building (for windward, side and leeward face of the building) for $0^{\circ}$ angle of incidence are shown in Figures 18 to 21, for all other angles kindly refer to Report No.397, School of the Built-Environment, Oxford Brookes University, Oxford, U.K. ISBN: 978-0-9556254-3-5 (Irtaza et al, 2010).

It was observed that the maximum pressures coefficients (negative/suction) on the roof of the cubical SEB occurred when the direction of wind was at $\pm 45^{\circ}$ from the normal windward façade. The maximum positive pressure on the windward face of the SEB occurred when the direction of the wind was perpendicular to its windward face. The maximum negative pressure on the side face of the SEB was when the direction of flow was parallel to the side face. The maximum negative pressure (suction) on the leeward face of the SEB was when the direction of wind is at $\pm 30^{\circ}$ from the windward façade.

The model of the above SEB was also analyses by various techniques of Computational Fluid Dynamics (CFD). The results obtained from various CFD techniques were validated from the experimental results (wind-tunnel tests on SEB) on SEB and the fullscale test data obtained from the work of Richards and Hoxey (Richards and Hoxey, 1999).

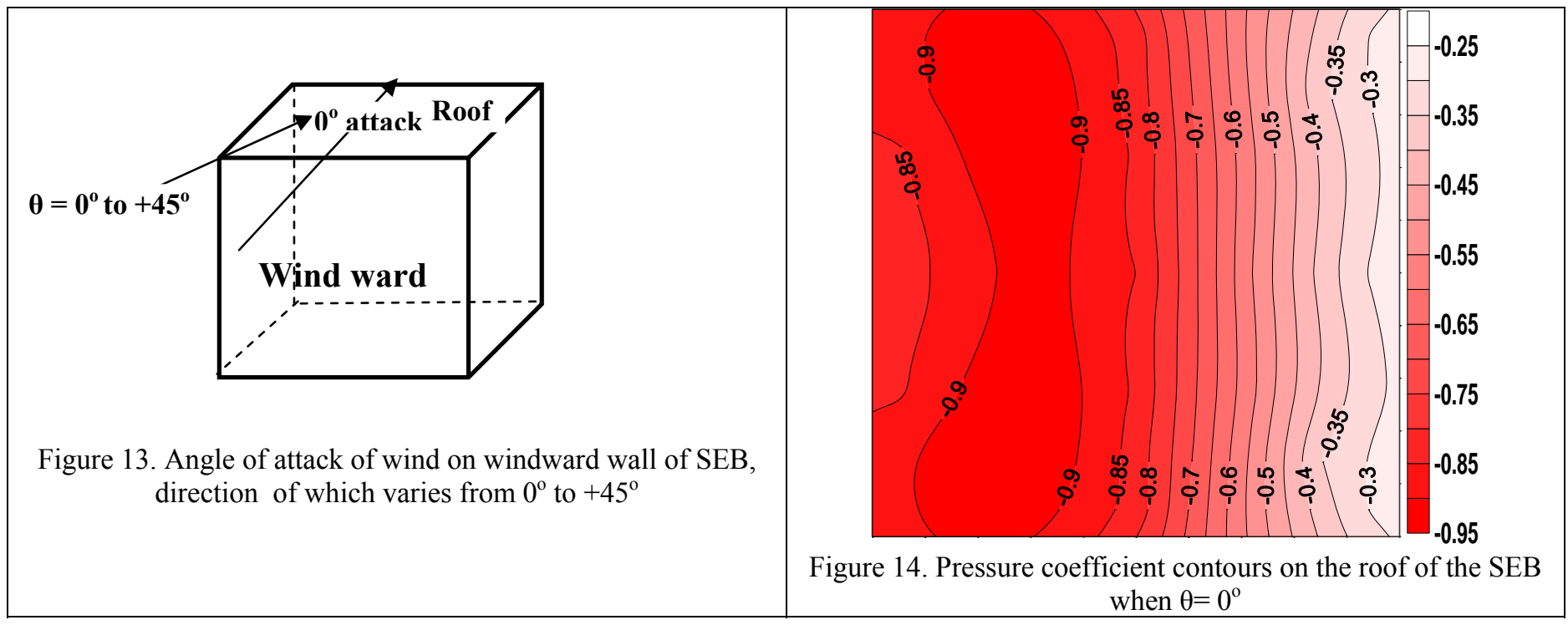




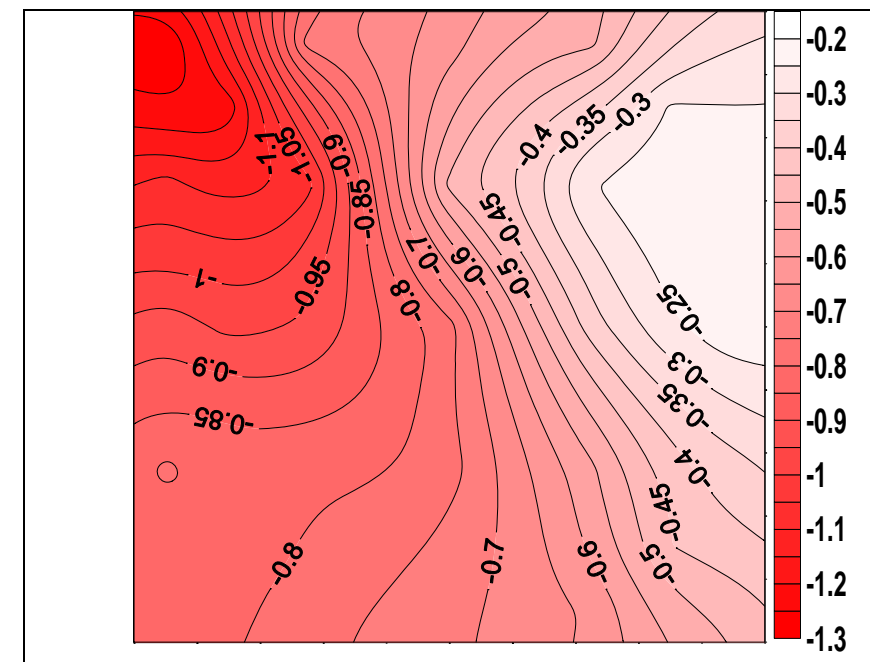

Figure 15. Pressure coefficient contours on the roof of the SEB when $\theta=15^{\circ}$

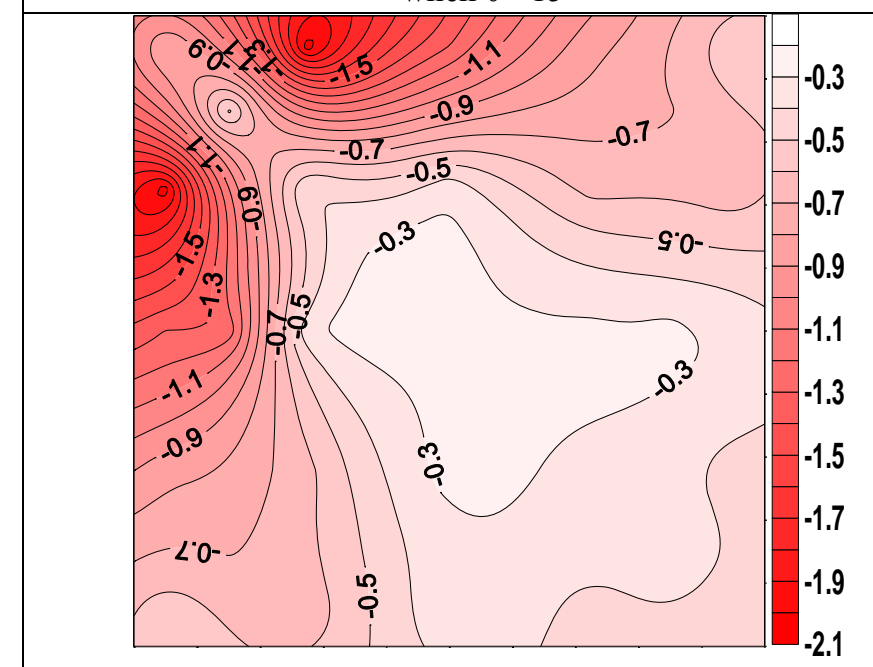

Figure 17. Pressure coefficient contours on the roof of the SEB when $\theta=45^{\circ}$

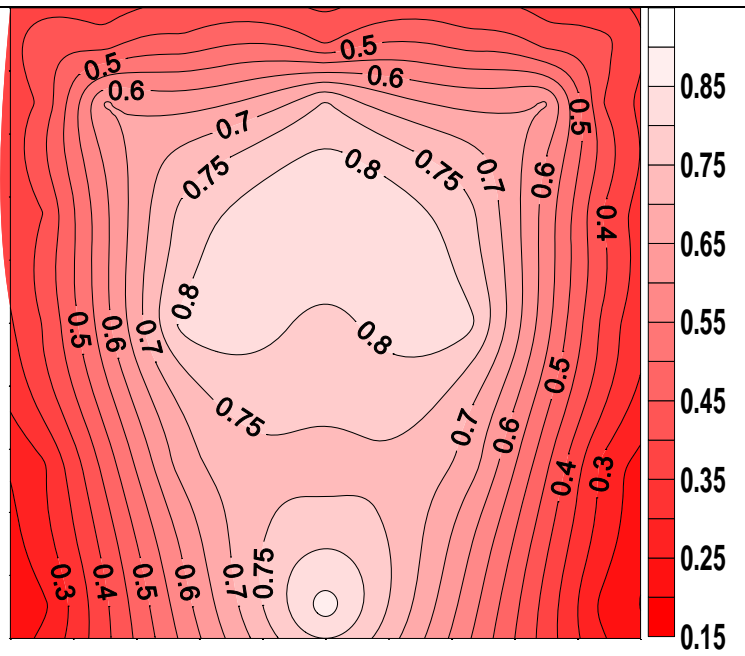

Figure 19. Pressure coefficient contours on the windward face of the SEB when $\theta=0^{\circ}$

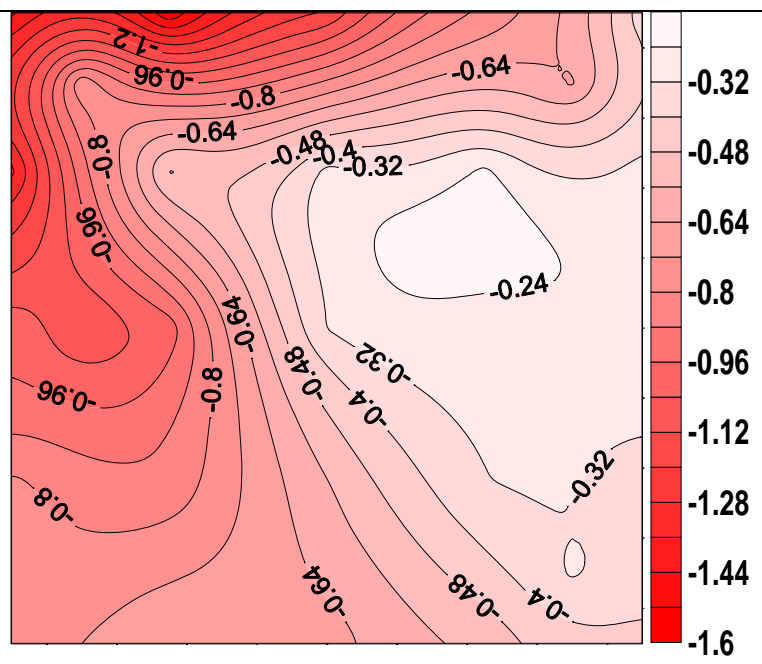

Figure 16. Pressure coefficient contours on the roof of the SEB when $\theta=30^{\circ}$

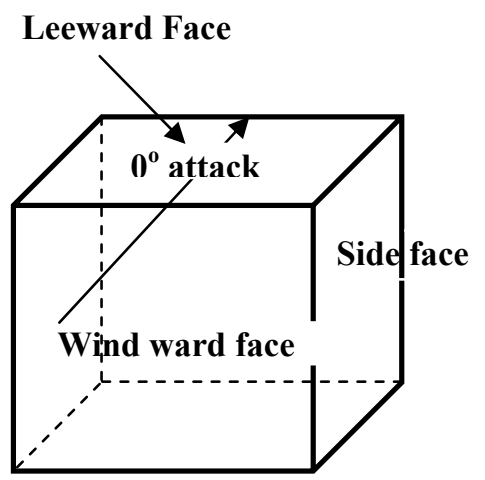

Figure 18. Angle of attack of wind on windward wall of SEB

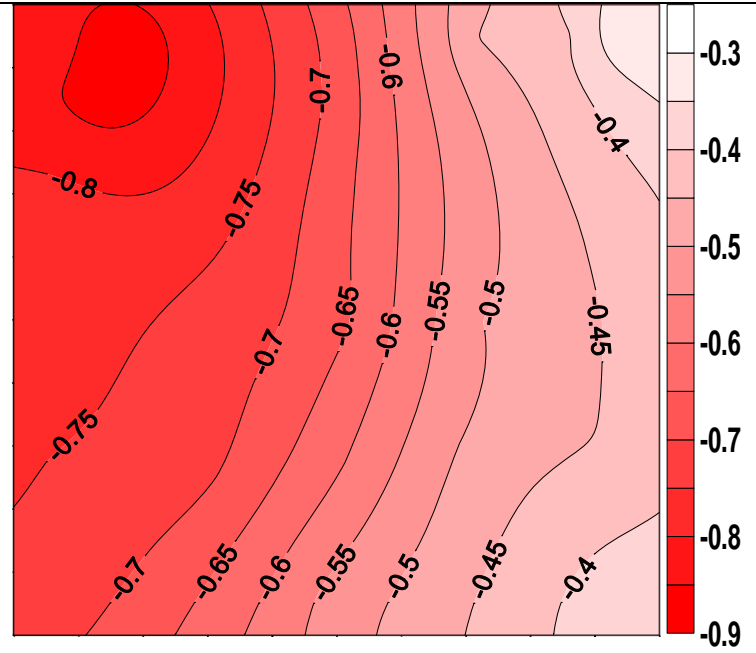

Figure 20. Pressure coefficient contours on the side face of the building when $\theta=0^{\circ}$ 


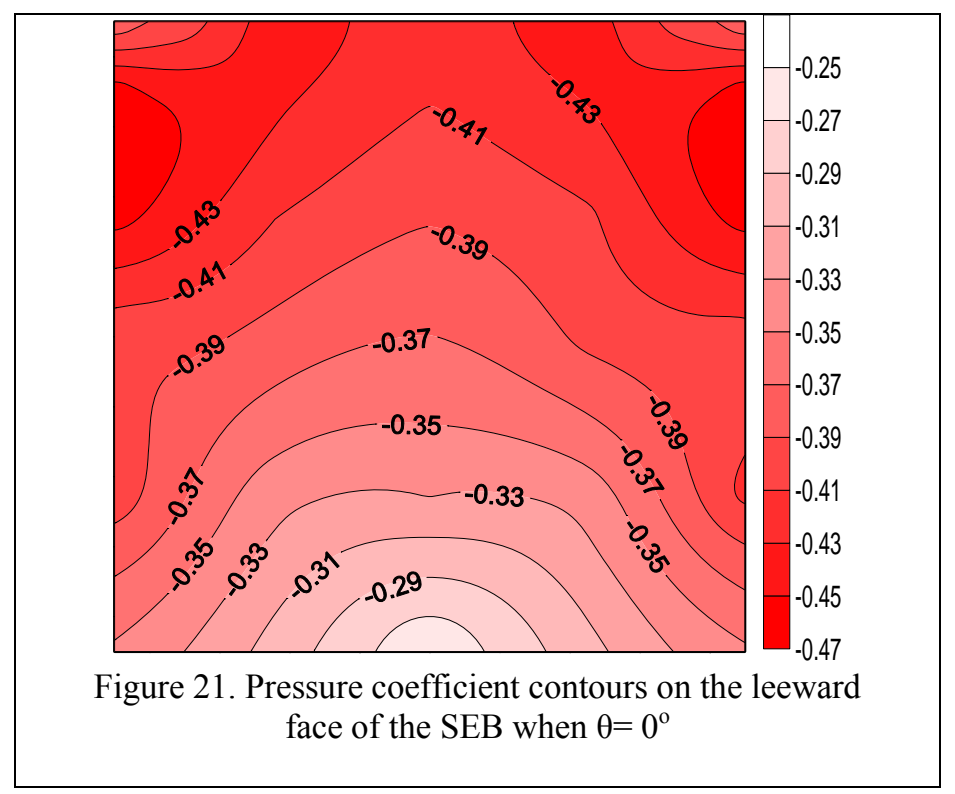

The CFD results presented thus far are not as good as might be hoped, although they do display the correct magnitude and trends in many cases. It was apparent that none of the models tested could accurately predict the experimentally obtained leeward pressure distribution.

It was found that Reynolds Stress method did not converge to an accurate solution when unstructured meshes were used. Therefore, structured meshes were created for the RSM and combinations of both structured and unstructured meshes were used for the remaining models to study the pressure coefficients on the façade of the SEB.

A comparison of the results of wind-tunnel experiments, full-scale and CFD analyses on the SEB can be seen in Figures 22 to 24. It can be seen from the study of the SEB that the Standard $k-\varepsilon$ model over-predicted the pressure coefficients by approximately $20-25 \%$ at the flow stagnation point. The large eddy simulation model predicted the most accurate results on the windward face. The remaining models, i.e. the Reynolds stress model, the RNG $k-\varepsilon$ and the Realizable $k-\varepsilon$ showed similar patterns of the pressure coefficient distribution on the windward face where the pressure coefficients were approximately 10-15 percent higher than the experimentally obtained values. All the models analysed predicted lesser pressure coefficients on the trailing edge of the side face with the RNG $k-\varepsilon$ closer to the experimental data. In the leading edge of the side face the Standard $k-\varepsilon$ and the Realizable $k-\varepsilon$ predicted a little higher pressure coefficient whilst the LES value was near the experimental data. The reason may be due to the over production of the turbulent kinetic energy near the sharp edges. It was again apparent that none of the models tested except the LES (which is near to the experimental value) could accurately predict the experimentally obtained leeward pressure distribution. It was also observed that the Reynolds stress method does not converge when unstructured meshes were used. Except for the Reynolds stress model, both structured and unstructured meshes were used. Structured meshes were created for the Reynolds stress model.

It should be noted that there are a few inconsistent experimental points both on the side wall and most noticeably on the roof of the cube that cannot be fully explained. These errors are most likely due to approach flow turbulence intensity variations. These possible errors should be the subject of further investigations.

It was again apparent that none of the models tested could accurately predict the experimentally obtained distribution on the leeward face. The best results were obtained from the Large Eddy Simulation although errors of approximately of 15-20 percent were still apparent. From the models the worst results were in error by up to $60-80 \%$. It appears that the under prediction of negative pressures are a consequence of over-prediction of the wake recirculation and a corresponding lack of velocity deficit. These results confirm the need to accurately simulate the flow field around a bluff body, particularly the leeward wake region. No improvements were found with grid refinement. The flow patterns predicted by the present numerical study are shown in Figures 25 to 30 . 


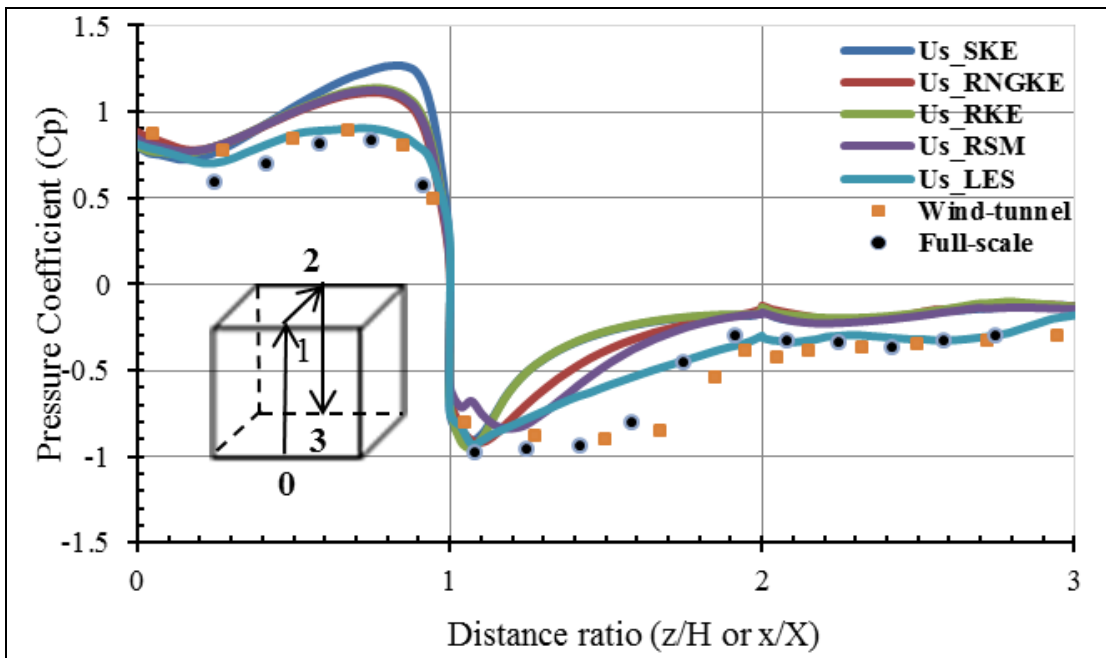

Figure 22. Pressure coefficient contours along the mid-width of the SEB

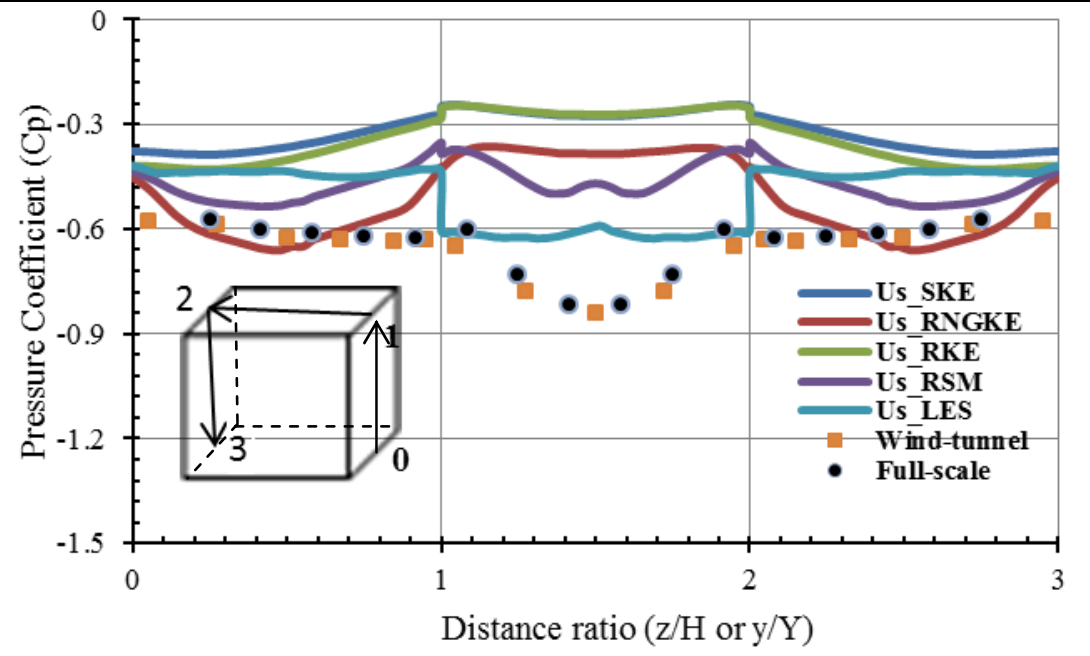

Figure 23. Pressure coefficients contour along the mid-depth of the SEB

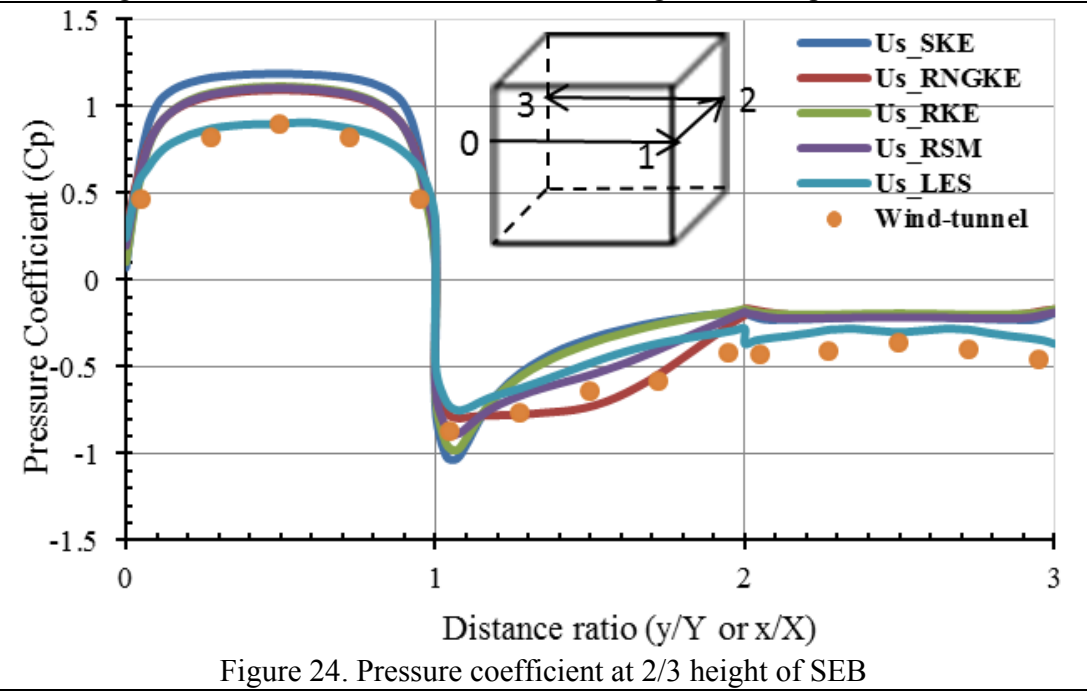




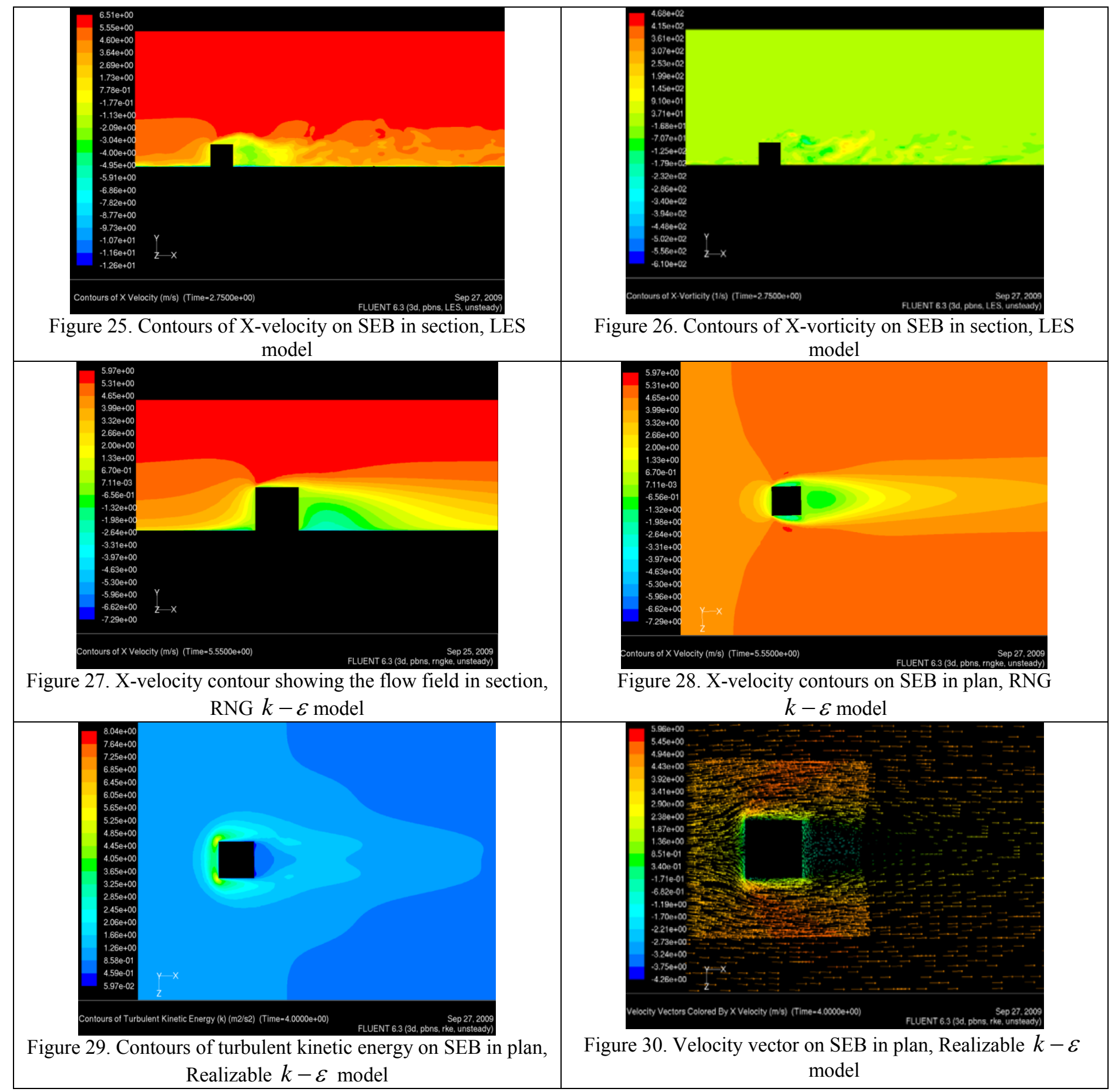

\section{Conclusions}

The experimental data of cubical SEB from SRI for full-scale structures and wind-tunnel test on SEB has enabled both novel and high quality analysis of the accuracy of the state of the art CFD turbulence models when applied to wind engineering studies. Development work on commercial CFD code has seen the successful implementation and testing of state of the art methods of modeling turbulence and fluid flow. The investigation suggests that a suitable turbulence model for wind engineering should be able to model the anisotropy of turbulent flow. This is because the wind engineering flows are inherently anisotropic and secondly to aid correct calculation of turbulent kinetic energy production term.

It should be stated that none of the RANS models provide accurate results for the whole range of test cases, with errors sometimes nearly 20-50 percent. This suggests the eventual need to reduce the importance of the turbulence model and the necessity to resolve more of the flow field directly, i.e. the Large Eddy Simulation. The results also show inadequacies of the standard $k-\varepsilon$ 
model in wind engineering flows. The ad-hoc modifications to turbulence models are generally unsatisfactory. The Reynolds stress method is highly numerically unstable.

$\begin{array}{ll}\text { Nomenclature } & \\ \text { B } & \text { Width of the cubical SEB } \\ \text { CAARC } & \text { Commonwealth advisory aeronautical council } \\ \text { CFD } & \text { Computational fluid dynamics } \\ \text { CWE } & \text { Computational wind engineering } \\ \text { DNS } & \text { Direct numerical simulation } \\ \text { LES } & \text { Large eddy simulation } \\ \text { RANS } & \text { Reynolds averaged Navier-Stokes } \\ \text { Re } & \text { Reynolds number } \\ \text { RKE } & \text { Realizable } k-\varepsilon \\ \text { RNG } & \text { Renormalization group } \\ \text { RNGKE } & \text { Renormalization group } k-\varepsilon \\ \text { RSM } & \text { Reynolds stress method } \\ \text { SEB } & \text { Silsoe experimental building } \\ \text { SKE } & \text { Standard } k-\varepsilon \\ \text { SRI } & \text { Silsoe Research Institue } \\ k & \text { Turbulent kinetic energy } \\ \varepsilon & \text { The dissipation of turbulent kinetic energy } \\ \rho & \text { Density of air } \\ u_{\tau} & \text { Ground shear stress } \\ \mu & \text { Kinematic viscosity of air } \\ y & \text { Distance from the wall to the centre of first cell. }\end{array}$

\section{References}

Cook N.J. and Mayne J.R. 1981. 'A novel working approach to the assessment of wind loads for equivalent static design a refined working approach to the assessment of wind loads for equivalent static design', Journal of Wind Engineering and Industrial Aerodynamics, Vol. 8, Issue 3, pp.299-301.

Fluent 6.3 Inc. 2006. 'The user's guide'.

Huang S., Li Q.S. and Xu S, 2007. 'Numerical evaluation of wind effects on tall steel building by CFD', Journal of Construction Steel Research, Vol. 63, Issue 5, pp. 612-627.

Frank W. and Mauch H. 1993. 'Large-eddy-simulation of the flow around building models', Journal of Wind Engineering and Industrial Aerodynamics, Vol. 46-47, pp: 213-218.

Ghosh A.K. 2004. 'Computational wind engineering - prospects and challenges', International Workshop on Wind Engineering and Science (WES-04), Elite Publishing House Pvt. Ltd., New Delhi, pp 107-120.

Gao Y. and Chow W.K. 2005. 'Numerical studies on air flow around a cube'. Journal of Wind Engineering and Industrial Aerodynamics, Vol. 93, No. 2, pp. 115-135.

Hoffman J. and Johnson C. 2006. 'A new approach to computational turbulence modelling'. Computer Methods in Applied Mechanics and Engineering, Vol. 195, No. 23-24, pp. 2865-2880.

Irtaza H., Beale R.G., Godley M.H.R., 2010. 'Wind tunnel investigation of the pressures acting on sheet clad scaffolds', Report No.397, School of the Built-Environment, U.K. ISBN: 978-0-9556254-3-5, Printed in Great Britain by Oxford Brookes University, Oxford, U.K.

Kasperski M. and Hoxey R., 2008. 'Extreme-value analysis for observed peak pressures on the Silsoe cube', Journal of Wind Engineering and Industrial Aerodynamics, pp. 994-1002, 96.

Launder B.E. and Spalding D.B. 1972. 'Mathematical model of turbulence', Academic Press Inc. (London) Limited, U.K.

Murakami S. and Mochida A. 1995. 'On turbulent vortex shedding flow past 2D square cylinder predicted by CFD', Journal of Wind Engineering and Industrial Aerodynamics, Vol. 54-55, pp: 191-211.

Murakami S. 1998. 'Overview of turbulence models applied in CWE-1997', Journal of Wind Engineering and Industrial Aerodynamics, Vol. 74-76: pp. 1-24.

Panofsky H.A., Dutton J.A. 1984. 'Atmospheric Turbulence: Models and Methods for Engineering Applications', Wiley, New York.

Richards P.J., Hoxey R.P., Connell B.D., Lander D.P. 2007. 'Wind-tunnel modelling of Silsoe Cube', Journal of Wind Engineering and Industrial Aerodynamics, pp. 1384-1399. 
Richards P.J., Hoxey R.P. 2008. 'Wind loads on the roof of a $6 \mathrm{~m}$ cube', Journal of Wind Engineering and Industrial Aerodynamics, pp. 984-993, 96.

Richards P.J. and Hoxey R.P. 1999. 'Spectral models of the atmospheric surface layer', 10 ${ }^{\text {th }}$ ICWE, Copenhagen, June 1999.

Richards P.J. and Hoxey R.P. 1993. 'Appropriate boundary conditions for computational wind engineering models using the $k-\varepsilon$ turbulence model', Journal of Wind Engineering and Industrial Aerodynamics, Vol. 46-47, pp. 145-153.

Rodi W. 1997. 'Comparison of LES and RANS calculations of the flow around bluff bodies', Journal of Wind Engineering and Industrial Aerodynamics, Vol. 69-71: pp. 55-75.

Rodi W. 1993. 'On the simulation of turbulent flow past bluff bodies', Journal of Wind Engineering and Industrial Aerodynamics, Vol. 46-47, pp: 3-19.

Saathoff P.J., Mebourne W.H., 1986. 'Free stream turbulence and wind-tunnel blockage effects on streamwise surface pressures', Journal of Wind Engineering and Industrial Aerodynamics, 26, pp. 353-370.

Ahmad S., Kumar K. 2002. 'Effect of geometry on wind pressures on low-rise hip roof buildings', Journal of Wind Engineering and Industrial Aerodynamics, 90, 755-779.

Scruton, C. 1981. 'An introduction to wind effects on structures', Engineering Design Guides, Vol. 40. Oxford University Press.

Shih T.-H., Liou W.W., Shabbir A., Yang Z. and Zhu J. 1995. 'A New $k-\varepsilon$ eddy-viscosity model for high Reynolds number turbulent flows - model development and validation', An International Journal of Computers and Fluids (Elsevier), Vol. 24, No. 3, pp. 227-238.

Smirnov R., Shi S., Celik I. 2001. 'Random flow generation technique for large eddy simulations and particle-dynamics modelling', Journal of Fluids Engineering, 123: 359-71.

Wright N.G. and Easom G.J. 2003. 'Non-linear $k-\varepsilon$ turbulence model results for flow over a building at full-scale', Applied Mathematical Modelling (Elsevier), Vol. 27, 1013-1033.

Yakhot V. and Orszag S.A. 1986. 'Renormalization Group Analysis of Turbulence: I. Basic Theory', Journal of Scientific Computing, Vol. 1, No. 1, pp. 3-51.

\section{Biographical notes}

Dr. Hassan Irtaza, Associate Professor, Department of Civil Engineering, Aligarh Muslim University, Aligarh, India. Ph.D. awarded from Oxford Brookes University, Oxford, U.K. in the area of Wind Engineering and Computational Fluid Dynamics and having teaching and research experience of more than seventeen years. Areas of research are wind engineering, earthquake engineering and structural dynamics.

R.G. Beale, Principal Lecturer, Director of Collaborative Provision, Department of Mechanical Engineering and Mathematical Sciences. Working in Oxford Brookes University since 1971 over various capacity. Completed PhD by published works in 2004. Has published over 40 departmental and other reports with reference to consultancy under taken in scaffolding and racking structures as well as Engineering Mathematics. Guided more than $15 \mathrm{PhD}$ students. Areas of interests are semi-rigid connections, pallet racks and scaffold structures, finite element modeling, computational fluid dynamics etc. Authored the commercial program 'Pallet' for the design and analysis of pallet rack structures according to a finite element modelling code. Having more than 80 research papers in refereed journals and conferences. Examined more than $20 \mathrm{PhD}$ theses.

M.H.R. Godley is an associate member of the CPM group and based at the Department of Architecture. Dr. Godley retired from full-time employment as Acting Head of the School of Construction and Earth Sciences in 1998 having taught for 20 years in the Department of Civil Engineering. During all this period he maintained close contact with industry generating funds to support research by providing consultancy services for Industry, mainly in the field of specialist structural testing. His field of interest is the design and analysis of structures which are especially susceptible to structural instability, most notably scaffolding structures, both proprietary systems and tube and fitting scaffolds, and storage structures for warehouses fabricated from cold formed steel sections. Since retirement he has run his own successful consultancy, Slender Structures Ltd. and maintains his involvement in research through the supervision, with Rob Beale, of three research students. He is the joint author of a Code of Practice for the Design of Steel Storage Structures for Europe published by the Federation Europeenne de la Manutention (FEM) which was the basis of EN15512 (2009) and is the author of the Guide to good practice for scaffolding with Tubes and Fittings published by the National Access and Scaffolding Confederation (NASC) in the UK.

Azhar Jameel, Associate Professor, Civil Engineering Section, University Polytechnic, Aligarh Muslim University, Aligarh, India, having teaching experience of both undergraduate and postgraduate students of more than 28 years.

Received July 2012

Accepted October 2012

Final acceptance in revised form October 2012 